in the reports to summarise opinion and the readability level using an imbedded Microsoft office programme that provides a result comparable to school age literacy level. This information was then collated and analysed between the trusts.

The extracted statements were then used to undertake a multiagency survey to explore how different professionals interpret statements

Results 35 different statements were used in the report opinions. Two statements were used commonly. These were 'consistent' as in 'this mark is consistent with' and 'likely/unlikely' A quarter of disseminated reports had spelling errors and $27 \%$ were felt to have no clear opinion

Only $17 \%$ had a readability level likely to be readable to most adults of all literacy abilities

29 professionals completed the survey, primarily from safeguarding social work or paediatric background.

The statement with the best concordance between practitioners and shortest range of responses was 'this is highly likely to be due to non-accidental injury'. For this statement the surety of the practitioner that the presentation was due to child abuse was $90 \%$ (range $75 \%$ to $99 \%$ )

There was discordance amongst practitioners in many responses and the surety range was often wide.

\section{G151(P) SUPPORTING PARENTS OF SEXUALLY EXPLOITED YOUNG PEOPLE: AN EVIDENCE REVIEW}

D McNeish, S Scott. Research, DMSS Research, North Dalton, UK

\subsection{6/archdischild-2018-rcpch. 147}

Background Positive relationships with parents are important protective factors in young people's lives.

This review gathers evidence on what is helpful in enabling parents to maintain or rebuild good relationships where a child has been sexually exploited or serious concerns exist.

Methods The research draws on evidence from the limited research around parenting and child sexual exploitation, supplementing this with evidence from family support and parenting research more broadly.

The search strategy included

- A search of websites including those of relevant government departments, voluntary organisations and think-tanks.

- A search of multiple databases, published research, research in progress and grey literature.

The parameters of the search strategy were literature with a specific focus on 'parents' and 'child sexual exploitation' and studies of parenting in adversity.

Results A substantial amount of research which can offer valuable transferable lessons was identified.

The loudest message was that practitioners need to start with a focus on the strengths of parents and avoid assumptions of deficit or blame. Fundamentally, parents want service providers to work with them as partners in supporting their child and to be seen as part of the solution

There are some key areas in which parents will have strengths but may also experience difficulties. The difficulties experienced include:

- Parents' social support networks may be compromised by the stigma associated with sexual exploitation and the lack of understanding they may encounter within their wider family/ community.

- Their capacity for coping will be influenced by their own circumstances and their past experiences, and they will have different resilience factors in their lives.

- Parents will have different experiences of attachment, both from their own childhood and as parents.

There is good evidence that supporting parents has a direct effect on outcomes for their children.

Conclusions The report highlights the importance of supporting positive relationships which benefit the child, and outlines challenges for supporting parents and mechanisms for being more inclusive.

Overall, it gives a sense of parents as a key piece of the puzzle for addressing CSE more holistically.

\section{G152(P) PUKE AND PH}

L Rowley, K Ali, J Bursell, N Waters, M Aye. Paediatrics, Milton Keynes University Hospital, Milton Keynes, UK

\subsection{6/archdischild-2018-rcpch. 148}

Background A seven month old boy with gastro-oesophageal reflux, developmental delay and an inherited genetic abnormality had repeated admissions with vomiting and static weight. He was commenced on nasogastric (NG) feeds as he was found to have an unsafe swallow during an acute viral illness. His mother continued to report poor feed tolerance despite NG and nasojejunal (NJ) feeding.

Details of the case

During an inpatient stay at a different hospital it was observed that the mother would present 'well caught' vomitus to the nursing staff. The baby was not witnessed to be vomiting. In addition, a well secured $\mathrm{NJ}$ tube was reported by the mother to have accidentally been dislodged. These safeguarding concerns were shared with the local hospital.

On a subsequent admission to the local hospital with reported vomiting the baby was commenced on dioralyte via the NG tube. The mother continued to present 'vomit' in a bowl to nursing staff despite minimal nasogastric tube aspirates being observed. One episode raised particular suspicion as to the validity of the mother's claim.

$\mathrm{pH}$ indicator strips were used to determine the $\mathrm{pH}$ of the fluid which was presented as vomit. This was noted to be 7.5 (similar to tap water). An aspirate obtained from the baby's NG tube was 4.5 , which was similar to the $\mathrm{pH}$ of dioralyte.

The observed disparity led to initiation of child protection procedures on the basis that there was objective evidence of fabrication of illness.

Following separation from his mother the baby went on to tolerate milk feeds and solids with no vomiting. His faltering weight resolved.

Conclusion The use of $\mathrm{pH}$ indicator strips in this case confirmed the variance in $\mathrm{pH}$ between the gastric aspirate and the fluid presented by the mother as vomit. We propose the use of this simple bedside test in perplexing presentations with reported vomiting. One must remain cautious of the effect of anti-reflux medications on the $\mathrm{pH}$ of gastric fluid. It is imperative that the team consider chain of evidence and correct storage of specimens for use at a later date. 